Check for updates

Cite this: J. Mater. Chem. B, 2020 8, 5451

Received 12th March 2020

Accepted 5th May 2020

DOI: $10.1039 / d 0 t b 00679 c$

rsc.li/materials-b

\section{A covalent organic framework as a nanocarrier for synergistic phototherapy and immunotherapy $\dagger$}

\author{
Ying Zhou, ${ }^{\text {ab }}$ Sainan Liu, (D) ${ }^{\text {ac }}$ Chunling Hu, (D) ${ }^{\text {ac }}$ Lihan Cai ${ }^{a c}$ and Maolin Pang (D) tac $^{a c}$
}

As traditional cancer treatment methods, photodynamic therapy (PDT) and photothermal therapy (PTT) can eliminate primary tumors, but they cannot inhibit extensive tumor metastasis and local recurrence. Herein, in order to prevent intermolecular accumulation and improve photostability, indocyanine green (ICG) is spontaneously adsorbed onto a covalent organic framework (COF) with high affinity through $\pi-\pi$ conjugation, and then chicken ovalbumin (OVA) is coated on the surface of COF@ICG via an electrostatic interaction force. The resultant COF@ICG@OVA can ablate primary tumors under $650 \mathrm{~nm}$ and $808 \mathrm{~nm}$ laser irradiation due to its high photothermal conversion efficiency $(\eta=35.75 \%)$ and ability to produce reactive oxygen species (ROS). Tumor-associated antigens are also produced after combinational PTT/PDT therapy. By further combining with anti-PD-L1 checkpoint blockade therapy, it can effectively eliminate primary tumors and inhibit the metastasis of cancer cells by generating strong immune responses. Taken together, COFaICGaOVA nanoparticles offer an efficient synergistic therapeutic modality for the treatment of tumor metastasis.

\section{Introduction}

Cancer is the "number one killer" of today's human population. ${ }^{1}$ Relevant data show that $90 \%$ of cancer deaths can be ascribed to the tumor's local recurrence and extensive metastasis. ${ }^{2-4}$ Along with the growing understanding of how cancer interacts with the immune system, immunotherapies have become a hot topic in the field of cancer therapy, which mainly involve stimulating the body's inherent immune system to attack tumor cells., The current immunotherapies include cancer vaccination, ${ }^{7-9}$ immune checkpoint blockade, ${ }^{10,11}$ the chimeric antigen receptor for adoptive T-cell transfer (CAR-T), etc. ${ }^{12-15}$ However, solid tumor is difficult to be eliminated simply by antitumor immunotherapy, so it is necessary to combine it with other therapeutic methods to efficiently inhibit tumor growth and metastasis. ${ }^{16}$

Photodynamic therapy (PDT) and photothermal therapy (PTT) could inhibit tumor growth efficiently and simultaneously produce tumor-associated antigens (TAAs) to promote antitumor immune responses after elimination of the primary tumor. ${ }^{17-22}$ Dendritic cells (DCs) are natural immune cells, and TAAs can activate DCs to

\footnotetext{
${ }^{a}$ State Key Laboratory of Rare Earth Resource Utilization, Changchun Institute of Applied Chemistry, Chinese Academy of Sciences, Changchun 130022, P. R. China. E-mail: mlpang@ciac.ac.cn

${ }^{b}$ School of Chemistry \& Environmental Engineering, Changchun University of Science and Technology, Changchun, 130022, P. R. China

${ }^{c}$ University of Science and Technology of China, Hefei, Anhui, 230026, P. R. China $\dagger$ Electronic supplementary information (ESI) available: Additional SEM images, UV-vis spectra, DLS spectra, TGA data, photos of products, flow cytometric analyses, cytotoxicity test, slice and cell images, etc. See DOI: 10.1039/d0tb00679c
}

migrate to immune organs and secrete inflammatory cytokines. The antigen was presented to the T-cell receptor via the major histocompatibility complex (MHC)-antigen compounds, and then it initiated $\mathrm{T}$ cell-mediated cancer immunotherapy. ${ }^{23,24}$ Indocyanine green, an ideal photosensitizer that has been approved by the US Food and Drug Administration (FDA) for clinical use, has low toxicity and exhibits strong absorbance in the near infrared (NIR) region. However, the applications of ICG in tumor photothermal therapy are restricted due to its short half-life time and instability. ${ }^{25,26}$ Covalent organic frameworks (COFs) have been widely studied in various research fields. ${ }^{27-31}$ Attributed to their low density, adjustable pore size, and large surface area, recently, the application of COFs in the biomedical field has been reported by several groups. Owing to their extended conjugate structure and highly ordered $\pi-\pi$ stacking interaction, COFs can generate singlet oxygen $\left({ }^{1} \mathrm{O}_{2}\right)$ under laser irradiation. Therefore, the combination of COFs and ICG can not only improve the photostability of ICG without affecting its photothermal effect, but also utilize the photodynamic effect of COFs efficiently.

In this study, the COF based on 1,3,5-tris(4-aminophenyl)benzene (TAPB) and 1,3,5-benzenetricarbaldehyde (BTCA) was synthesized at room temperature via a Schiff base condensation reaction, and then ICG was conjugated with the COF to form COF@ICG (defined as CI). ${ }^{32}$ Finally, in order to improve the in vivo biocompatibility and the ability of generating endogenous antigens, chicken ovalbumin (OVA, $M_{\mathrm{W}} 43 \mathrm{kDa}$ ) was coated on the surface of COF@ICG to produce COF@ICG@OVA (abbreviated as CIO) (Fig. 1a). Upon near-infrared laser irradiation, CIO produced 
a

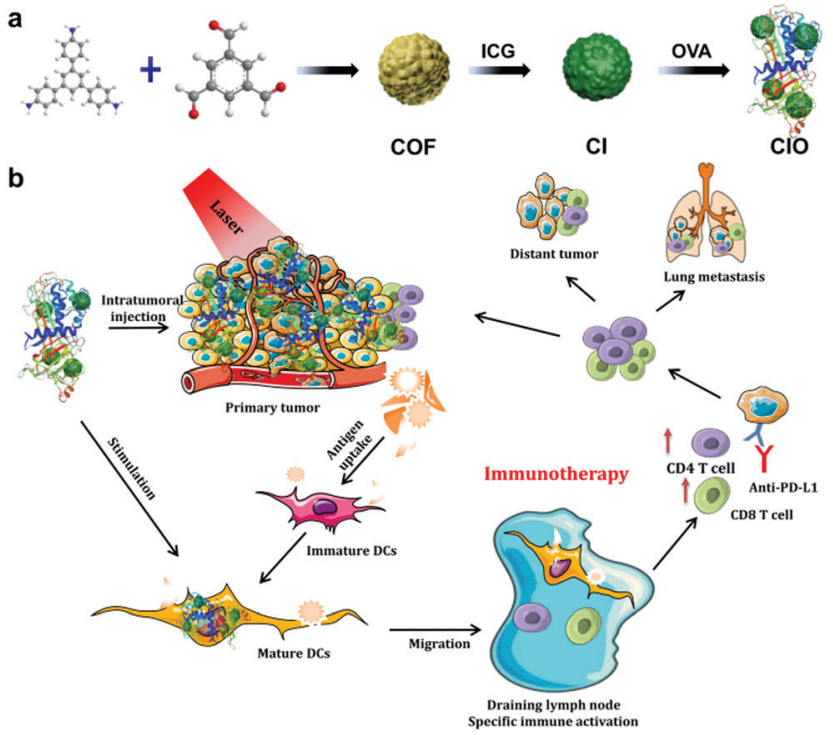

Fig. 1 (a) Fabrication and (b) mechanism of antitumor immune responses induced by $\mathrm{ClO}$ nanoparticle-based phototherapy combined with checkpoint blockade therapy.

abundant ROS and simultaneously induced hyperthermia. After combination with checkpoint blocking therapy, efficient tumor growth suppression and strong anti-tumor immunity to both primary and metastatic tumors were achieved (Fig. 1b).

\section{Experimental section}

\section{Chemicals and materials}

1,3,5-Benzenetricarbaldehyde $\left(\mathrm{C}_{9} \mathrm{H}_{6} \mathrm{O}_{3}, \quad \mathrm{AR}, \quad 98.0 \%\right.$, Yuhao Chemical), 1,3,5-tris(4-aminophenyl)benzene $\left(\mathrm{C}_{24} \mathrm{H}_{21} \mathrm{~N}_{3}, \mathrm{AR}, 98 \%\right.$, Alpha), methanol (AR, Beijing Chemical Works), acetonitrile$\left(\mathrm{CH}_{3} \mathrm{CN}, 99.8 \%\right.$, Vetec), acetic acid $\left(\mathrm{CH}_{3} \mathrm{COOH}\right.$, AR, Beijing Chemical Works), and $\mathrm{NH}_{2}-\mathrm{PEG}-2000-\mathrm{COOH}$ (Huawei Ruike chemical Co., Ltd) were used.

Cell lines and animals. L929 (mouse fibroblast cell line) and CT26 cells (mice colon cancer line) were chosen for cell tests. L929 and CT26 cells were purchased from the Institute of Biochemistry and Cell Biology, Chinese Academy of Sciences. L929 cells were first cultured in Dulbecco's Modified Eagle's Medium (DMEM) supplemented with 10\% heat-inactivated fetal bovine serum (FBS, GIBCO), 100 units per mL of penicillin and 100 units per mL of streptomycin (Sigma) in an atmosphere of $5 \% \mathrm{CO}_{2}$ at $37{ }^{\circ} \mathrm{C}$. CT26 cells were first cultured in Roswell Park Memorial Institute (RPMI/1640) medium supplemented with $10 \%$ heat-inactivated FBS, 100 units per $\mathrm{mL}$ of penicillin and 100 units per $\mathrm{mL}$ of streptomycin in an atmosphere of $5 \%$ $\mathrm{CO}_{2}$ at $37{ }^{\circ} \mathrm{C}$. Female BALB/c mice (18-20 g) were purchased from the Center for Experimental Animals, Jilin University (Changchun, China). All mice were handled using the protocol approved by the Institutional Animal Care and Use Committee of Jilin University.

Synthesis of COFs. $1.0 \mathrm{mg}(0.00595 \mathrm{mmol})$ of 1,3,5benzenetricarbaldehyde (BTCA) and $2 \mathrm{mg}(0.0056 \mathrm{mmol})$ of 1,3,5-tris(4-aminophenyl)benzene (TAPB) were dissolved in $2 \mathrm{~mL}$ of acetonitrile separately, and then the two solutions were mixed. Subsequently, $0.3 \mathrm{~mL}$ of acetic acid was added and the mixture was stirred at room temperature for $24 \mathrm{~h}$. The precipitate was collected by centrifugation and washed with ethanol three times.

Synthesis of COF@ICG. $1 \mathrm{mg}$ of COF was dispersed in $1 \mathrm{~mL}$ of deionized water. Then, $1 \mathrm{~mL}$ of ICG solution $\left(0.5 \mathrm{mg} \mathrm{mL} \mathrm{mL}^{-1}\right)$ was added to the mixture and stirred at room temperature for another $8 \mathrm{~h}$. The product (defined as CI) was collected by centrifugation and washed with deionized water three times.

Synthesis of COF@ICG@OVA. $5 \mathrm{mg}$ of CI and $5 \mathrm{mg}$ of OVA were dissolved in $4 \mathrm{~mL}$ of deionized water, and then the mixture was magnetically stirred for $12 \mathrm{~h}$ at room temperature. The products (defined as CIO) were collected by centrifugation and washed with deionized water three times.

\section{Characterization}

Powder X-ray diffraction (PXRD) studies were performed on a Rigaku MiniFlex 600 diffractometer with graphite monochromatized $\mathrm{Cu} \mathrm{K} \alpha$ radiation $(\lambda=0.15405 \mathrm{~nm})$. The sample was scanned at a scanning rate of $8^{\circ} \mathrm{min}^{-1}$ in the $2 \theta$ range from 2 to $20^{\circ}$ at room temperature. A field emission scanning electron microscope (FE-SEM, S-4800, Hitachi) equipped spectrometer was used to characterize the morphology of the sample. Transmission electron microscopy (TEM) images were obtained on an FEI Tecnai G2 S-Twin with a field emission gun operating at $200 \mathrm{kV}$. Thermogravimetric analysis data were recorded on a TGA 500 thermogravimetric analyzer by heating with a rate of $10{ }^{\circ} \mathrm{C} \mathrm{min}^{-1}$ under a nitrogen atmosphere $\left(60 \mathrm{~mL} \mathrm{~min}^{-1}\right)$. Fourier transform infrared (FT-IR) spectroscopy was performed on a Vertex PerkinElmer 580 BIR spectrophotometer (Bruker) using the $\mathrm{KBr}$ tabletting technique. The sample was securely packaged to obtain a transparent film. The UV-Vis adsorption spectral values were obtained on a U-3310 spectrophotometer (Hitachi). The X-ray photoelectron spectroscopy (XPS) spectra were recorded on a VG ESCALAB MK II electron energy spectrometer using $\mathrm{Mg}$ KR $(1253.6 \mathrm{eV})$ as the X-ray excitation source. The dynamic light scattering (DLS) experiment was performed using a Malvern Zetasizer-Nano ZS90 instrument at $25{ }^{\circ} \mathrm{C}$. MTT experiments were carried out using a microplate reader (Thermo Multiskan MK3).

\section{Photothermal heating experiments on CIO}

CIO aqueous solutions with different concentrations $\left(0-500 \mu \mathrm{g} \mathrm{mL}{ }^{-1}\right)$ were suspended in different wells of a 96-well plate, and irradiated with an $808 \mathrm{~nm}$ laser $\left(1.56 \mathrm{~W} \mathrm{~cm}^{-2}\right)$ for $5 \mathrm{~min}$. The temperatures were carefully measured every $15 \mathrm{~s}$ using a digital thermometer with a thermocouple probe. In order to test the photostability of CIO, the heating and cooling (ON-OFF) cycles were repeated more than five times under $808 \mathrm{~nm}$ laser irradiation $\left(1.56 \mathrm{~W} \mathrm{~cm}^{-2}\right)$. In each heating-cooling cycle, the CIO aqueous solution was irradiated for $10 \mathrm{~min}$ first followed by a $15 \mathrm{~min}$ cooling period until the temperature reached room temperature again. The in vivo analysis of the photothermal effect was achieved by intratumorally injecting CIO $\left(100 \mu \mathrm{g} \mathrm{mL}^{-1}\right)$ into tumor BALB/c mice. All of the temperatures were recorded by a photothermal camera every $15 \mathrm{~s}$. 


\section{Photothermal conversion efficiency of CIO}

The photothermal conversion efficiency was determined based on the protocol reported previously. ${ }^{33,34}$ First, the CIO aqueous solution was irradiated by an $808 \mathrm{~nm}$ laser for $10 \mathrm{~min}\left(1.56 \mathrm{~W} \mathrm{~cm}^{-2}\right)$ followed by a natural cooling period. During the cooling process, all of the temperatures were also carefully monitored every $15 \mathrm{~s}$ by a thermometer with a thermocouple probe. The photothermal conversion efficiency $(\eta)$ was calculated using the following equation:

$$
\eta=\frac{h S \Delta T_{\max }-Q_{\text {Dis }}}{I\left(1-10^{-A_{808}}\right)}
$$

where $h$ is the heat transfer coefficient, $S$ is the surface area of the container, $T_{\max }$ is the equilibrium temperature after $10 \mathrm{~min}$ of irradiation, $Q_{\mathrm{Dis}}$ expresses the heat dissipation by the test cell, $I$ is $808 \mathrm{~nm} \mathrm{CW}$ laser power $\left(1.2 \mathrm{~W} \mathrm{~cm}^{-2}\right)$, and $A_{808}$ is the absorbance of the CI@OVA aqueous solution at $808 \mathrm{~nm}$. The value of $h S$ was determined according to the following equation:

$$
h S=\frac{m_{\mathrm{d}} C_{\mathrm{d}}}{\tau_{\mathrm{s}}}
$$

where $m_{\mathrm{d}}$ is the mass $(0.4 \mathrm{~g})$ and $C_{\mathrm{d}}$ is the heat capacity $\left(4.2 \mathrm{~J} \mathrm{~g}^{-1}\right)$ of the aqueous solvent, $\tau_{\mathrm{s}}$ is the sample system time constant, and $\theta$ is defined as the ratio of $\Delta T$ and $\Delta T_{\max }$.

$$
t=-\tau_{\mathrm{s}}(\ln \theta)
$$

\section{Extracellular and intracellular ROS detection}

1,3-Diphenylisobenzofuran (DPBF) was employed as a chemical probe to evaluate the ${ }^{1} \mathrm{O}_{2}$ generation. Firstly, $10 \mathrm{mg}$ of DPBF was dissolved in $1 \mathrm{~mL}$ of DMSO to form a stable solution (37 mmol $\mathrm{L}^{-1}$ ). Secondly, an amount of CIO was dispersed evenly in $2 \mathrm{~mL}$ of deionized water in a quartz cell, and then $10 \mu \mathrm{L}$ of DPBE-DMSO solution was added. Before laser radiation, the mixed solution was tested via UV-Vis spectroscopy to confirm the initial absorption intensity of DPBF around $410 \mathrm{~nm}$. Then, the mixed solution was irradiated under a $650 \mathrm{~nm}$ laser for different times (0-12 min). The decrease in the DPBF absorption around $410 \mathrm{~nm}$ was monitored via UV-Vis spectroscopy at different time intervals. All experiments were carried out at room temperature under continuous stirring.

For in vitro ROS detection, ROS production was detected by a cell permeable dye, $2^{\prime}, 7^{\prime}$-dichlorofluorescin diacetate (DCFH-DA), which is non-fluorescent and could be easily oxidized to green fluorescent $2^{\prime}, 7^{\prime}$-dichlorofluorescein (DCF) by intracellular ROS. Briefly, CT26 cells were seeded into 6-well culture plates at a density of $0.8 \times 10^{5}$ cells per well and treated with (a) ICG; (b) $650 \mathrm{~nm}$ and $808 \mathrm{~nm}$ laser + ICG; (c) CIO only; (d) $650 \mathrm{~nm}$ and $808 \mathrm{~nm}$ laser + CIO. After $6 \mathrm{~h}$ of incubation in the dark, the culture media were replaced by fresh culture media, and exposed to $650 \mathrm{~nm}$ and $808 \mathrm{~nm}$ laser irradiation for $5 \mathrm{~min}$. Then, the ROS probe was added to each well and the mixture was incubated for $20 \mathrm{~min}$. Finally, the cells were washed repeatedly with PBS. The fluorescence was routinely detected by exciting at $485 \mathrm{~nm}$ and measuring emission at $545 \mathrm{~nm}$ with an inverted florescence microscope system (Nikon Ti-S).

\section{Cellular internalization of CIO}

CT26 cells were incubated with CIO $\left(50 \mu \mathrm{g} \mathrm{mL}^{-1}\right)$ for 1,3 , and $6 \mathrm{~h}$, respectively. They were then washed with PBS three times. The nuclei were labelled with 4,6-diamino-2-phenylindole (DAPI) for $10 \mathrm{~min}$ and then observed under a fluorescence microscope.

\section{In vitro cytotoxicity assay}

In order to study the in vitro biocompatibility of CIO, L929 cells were seeded into 96-well plates with a density of 6000 cells per well and cultured in DMEM for $24 \mathrm{~h}$. The original medium was then sucked out and the new medium containing different concentrations of CIO was added. After the cells were incubated for another $24 \mathrm{~h}$, the medium inside was again discarded and replaced with fresh DMEM containing $10 \mu \mathrm{L}$ of the standard methyl thiazolyl tetrazolium (MTT). After placing the plates in the dark for $4 \mathrm{~h}, 150 \mu \mathrm{L}$ of DMSO was added to each well and the absorption value of the medium was measured by a microplate reader at the wavelength of $490 \mathrm{~nm}$.

To study the in vitro PDT and PTT effect of CIO, four groups of CT26 cells were seeded into 96-well plates with a density of 6000 cells per well and cultured in RPMI medium for $24 \mathrm{~h}$. The original medium was then sucked out and the new medium containing different concentrations of CIO was added, respectively. After the cells were incubated for $4 \mathrm{~h}$, the medium inside was again discarded and replaced with fresh RPMI medium. One group of CT26 cells was not irradiated and the other three groups of CT26 cells were irradiated with a $650 \mathrm{~nm}$ laser $\left(0.72 \mathrm{~W} \mathrm{~cm}^{-2}\right)$, an $808 \mathrm{~nm}$ laser $\left(1.56 \mathrm{~W} \mathrm{~cm}^{-2}\right)$ and a combination of a $650 \mathrm{~nm}$ laser $\left(0.72 \mathrm{~W} \mathrm{~cm}^{-2}\right)$ and $808 \mathrm{~nm}$ laser $\left(1.56 \mathrm{~W} \mathrm{~cm}^{-2}\right)$ for $5 \mathrm{~min}$, respectively. Then, the cells were incubated for another $24 \mathrm{~h}$ before the MTT assay was used to detect the cell viability.

\section{Cell apoptosis of CIO nanoparticles}

To study the cell apoptosis process, the Annexin V-FITC/PI apoptosis detection kit was used. CT26 cells were treated with PBS, PBS + PDT, PBS + PTT, PBS + PDT + PTT, CIO $\left(50 \mu \mathrm{g} \mathrm{mL}^{-1}\right)$, $\mathrm{CIO}+\mathrm{PDT}\left(50 \mu \mathrm{g} \mathrm{mL}{ }^{-1}, 0.72 \mathrm{~W} \mathrm{~cm}^{-1}\right)$, CIO + PTT $\left(50 \mu \mathrm{g} \mathrm{mL}^{-1}\right.$, $\left.1.56 \mathrm{~W} \mathrm{~cm}^{-1}\right)$ and CIO + PDT + PTT $\left(50 \mu \mathrm{g} \mathrm{mL}^{-1}, 0.72 \mathrm{~W} \mathrm{~cm}^{-1}\right.$ and $1.56 \mathrm{~W} \mathrm{~cm}^{-1}$ ), respectively, and then the cells were incubated in 6-well plates overnight. After that, the cells were harvested and washed with PBS, and then resuspended with binding buffer $(400 \mu \mathrm{L})$. Finally, $5 \mu \mathrm{L}$ of Annexin V-FITC and $5 \mu \mathrm{L}$ of PI were utilized to stain the samples for $15 \mathrm{~min}$ and $5 \mathrm{~min}$ in the dark, respectively. The cell apoptosis process was monitored using a flow cytometer.

\section{In vivo combined therapy}

The development of the H22 (murine hepatoma) xenograft model was achieved by subcutaneous injection of $\mathrm{H} 22$ cancer cells into the left axils of BALB/c mice. When the tumor volume reached up to $80-120 \mathrm{~mm}^{3}$, cancer-bearing mice were randomly divided into eight groups, and treated with control, PDT, PTT, PDT + PTT, CIO, CIO + PDT, CIO + PTT and CIO + PDT + PTT, respectively. All groups of mice received treatment twice on day 
1 and day 7 by a $650 \mathrm{~nm}$ laser and an $808 \mathrm{~nm}$ laser with a power density of $0.72 \mathrm{~W} \mathrm{~cm}^{-2}$ and $1.56 \mathrm{~W} \mathrm{~cm}^{-2}$, respectively. The relative tumor volume was $V / V_{0}$ and the tumor volume was calculated by $V=4 / 3 \times$ length $\times$ width $^{2} / 8$, where $V_{0}$ was the tumor volume before treatment.

To establish the CT26 orthotopic murine breast cancer model with spontaneous metastasis, mice were divided into groups randomly. For the first tumour inoculation, CT26 cells $\left(1 \times 10^{6}\right)$ suspended in PBS were subcutaneously injected into the left flank of each female BALB/c mouse. For the second tumour inoculation, which was conducted 7 days later, CT26 cells $\left(4 \times 10^{5}\right)$ suspended in PBS were subcutaneously injected into the right flank of each female BALB/c mouse. When the primary tumors reached about $100 \mathrm{~mm}^{3}$ in volume, mice were divided into four groups: (1) control, (2) anti-PD-L1, (3) CIO + PDT + PTT, and (4) CIO + PDT + PTT + anti-PD-L1. Mice were injected intratumorally with CIO $\left(100 \mu \mathrm{L}, 100 \mu \mathrm{g} \mathrm{mL}{ }^{-1}\right)$ for $4 \mathrm{~h}$ and received $650 \mathrm{~nm}+808 \mathrm{~nm}$ laser at $0.72 \mathrm{~W} \mathrm{~cm}^{-2}$ and $1.56 \mathrm{~W} \mathrm{~cm}^{-2}$ for $5 \mathrm{~min} .2 \mathrm{mg}$ of anti-PD-L1 in $200 \mu \mathrm{L}$ of PBS was injected intravenously on day $1,3,5$ and 7 . The tumor length and width of the primary tumor and distant tumor were measured every two days.

\section{Biodistribution and metabolism of CIO nanoparticles in vivo}

The CIO nanoparticles at a dose of $20 \mathrm{mg} \mathrm{kg}^{-1}$ were intravenously injected into 18 healthy Balb/c mice separately. Then, the main organs, such as heart, liver, spleen, lungs and kidneys, were collected and weighed at different times $(1 \mathrm{~h}, 5 \mathrm{~h}, 12 \mathrm{~h}, 1 \mathrm{~d}, 3 \mathrm{~d}$ and 7 d). Each organ section was treated with $\mathrm{HNO}_{3}$ and $\mathrm{H}_{2} \mathrm{O}_{2}$ $(\mathrm{v} / \mathrm{v}=1: 1)$ at $60{ }^{\circ} \mathrm{C}$. Finally, the concentration of $\mathrm{Fe}$ was measured by ICP-MS. For monitoring the metabolic process, three healthy Balb/c mice were intravenously injected with CIO nanoparticles at a dose of $20 \mathrm{mg} \mathrm{kg}^{-1}$, then feces samples were collected from each mouse (at 1, 2, 3, 5 and 7 days post-injection of CIO nanoparticles) and measured by ICP-MS.

\section{Cytokine detection}

Splenic supernatants were isolated from mice after various treatments and diluted for analysis. The tumor necrosis factor (TNF-a, BioLegend) and IL-6 (BioLegend) were analyzed with ELISA kits according to the vendors' protocols. Primary tumor supernatants were isolated from mice after various treatments and diluted for analysis. Interleukin 10 (IL-10) and transforming growth factor beta 1 (TGF- $\beta 1$ ) were analyzed with ELISA kits according to the vendors' protocols.

\section{In vivo analysis of $\mathrm{T}$ cells}

To study the immune cells in distant tumors and the spleen, tumors and spleen were harvested from mice in different treatment groups. Then, tumor tissues were cut into small pieces and put into a glass homogenizer containing PBS ( $\mathrm{pH} 7.4$ ) with $2 \%$ heatinactivated fetal bovine serum. Then, the single-cell suspension was prepared under gentle pressure with a homogenizer without addition of digestive enzyme. After that, cells were washed with PBS ( $\mathrm{pH}$ 7.4) and filtrated with a cell sieve of 200 mesh. The remaining cells were centrifuged twice for $10 \mathrm{~min}$ at $1000 \mathrm{rpm}$. Then, the cells were diluted to $10^{6} / 100 \mu \mathrm{L}$ and stained with
CD3 antibody, CD4 antibody, and CD8 antibody, respectively, according to the manufacturer's protocols. Finally, flow cytometry analysis was performed according to the manufacturer's instructions.

\section{Results and discussion}

\section{Synthesis and characterization of CIO}

As shown in Fig. 2a-c and Fig. S1 (ESI $\dagger$ ), the scanning electron microscopy (SEM) and transmission electron microscopy (TEM) images show that highly monodispersed spherical COF nanoparticles with an average size of approximately $100 \mathrm{~nm}$ were produced and the mean size increased a little bit after loading ICG and OVA. ${ }^{26,33,34}$ Fig. $2 d$ shows that the zeta potentials of the COF, CI and CIO were $-33.6,-36.8$ and $-29.1 \mathrm{mV}$, respectively. The diffraction peaks of the as-synthesized nanoparticles in the powder X-ray diffraction (PXRD) patterns matched very well with the standard diffraction peaks of the COF (Fig. 2e). ${ }^{35}$ Fig. $2 f$ shows the Fourier transform infrared (FT-IR) spectra of the COF, $\mathrm{CI}$ and CIO, respectively. For the COF, the disappearance of the $\mathrm{N}-\mathrm{H}$ stretching band at $3000-3500 \mathrm{~cm}^{-1}$, the decrease of intensity for the $\mathrm{C}=\mathrm{O}$ stretching band at $1689 \mathrm{~cm}^{-1}$ and the appearance of the $\mathrm{C}=\mathrm{N}$ stretching band at $1623 \mathrm{~cm}^{-1}$ demonstrated the successful synthesis of the COF. ${ }^{34}$ For CIO, the characteristic absorption bands of $-\mathrm{OH}\left(3291 \mathrm{~cm}^{-1}\right)$, amide I $\left(1650 \mathrm{~cm}^{-1}\right)$ and amide II $\left(1531 \mathrm{~cm}^{-1}\right)$ testified the successful loading of ICG and OVA. ${ }^{36}$ In addition, according to the UV-vis spectra (Fig. S2 and S3, ESI $\dagger$ ), the loading efficiency of ICG and OVA was around $29.3 \%$ and $40.44 \%$, respectively. Moreover, after being immersed in water, phosphate buffer solution (PBS), Roswell Park Memorial Institute-1640 (RPMI-1640) and 10\% fetal bovine serum (FBS) for 5 days, the CIO particles showed good stability and dispersity (Fig. S4, ESI $\dagger$ ). The collapsing temperature of $\mathrm{CIO}$ was approximately $250{ }^{\circ} \mathrm{C}$ as measured by thermogravimetric analysis (TGA, Fig. S5, ESI $\dagger$ ).

\section{Photodynamic and photothermal effect of CIO in vitro}

According to the UV-vis spectra in Fig. S6 (ESI $\dagger$ ), CIO shows strong absorption at $820 \mathrm{~nm}$ and $420 \mathrm{~nm}$, and weak absorption
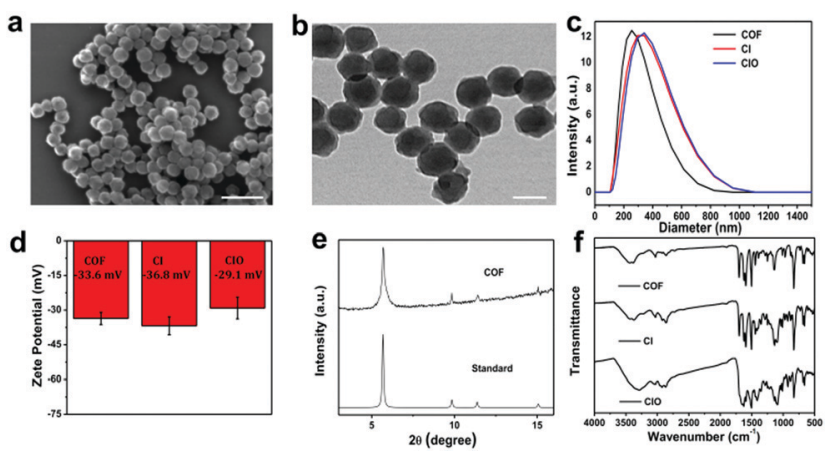

Fig. 2 (a) SEM image (scale bar is $200 \mathrm{~nm}$ ) and (b) TEM image (scale bar is $50 \mathrm{~nm}$ ) of $\mathrm{ClO}$ nanoparticles. (c) Average hydrodynamic size and (d) zeta potentials of COF, $\mathrm{Cl}$ and $\mathrm{ClO}$ nanoparticles. (e) PXRD patterns of the COF. (f) FT-IR spectra of COF, $\mathrm{Cl}$ and $\mathrm{ClO}$ nanoparticles. 

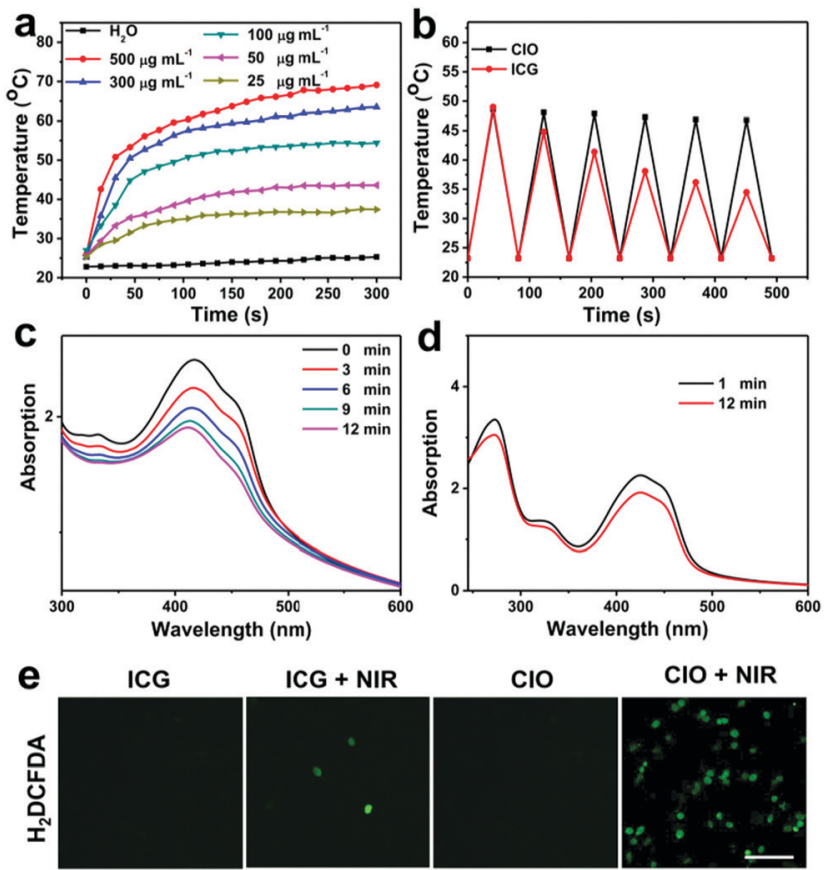

Fig. 3 (a) Temperature variation curves for $\mathrm{ClO}$ solutions under $808 \mathrm{~nm}$ laser irradiation. (b) Heating profiles of free ICG and CIO ([ICG] $=4 \mu \mathrm{g} \mathrm{mL}^{-1}$ ) in water during six laser on/off cycles under NIR laser irradiation $\left(1.0 \mathrm{~W} \mathrm{~cm}^{-2}\right)$. (c) UV spectra of DPBF solutions in the presence of COF nanoparticles and (d) in the absence of COF nanoparticles under laser irradiation $(650 \mathrm{~nm}$, $0.72 \mathrm{~W} \mathrm{~cm}^{-2}, 12 \mathrm{~min}$ ). (e) Inverted fluorescence microscopy images of CT26 cells after different treatments: ICG, ICG + NIR laser irradiation, and $\mathrm{CIO}$ without or with NIR laser irradiation. DCF represents the presence of ROS (scale bar $=100 \mu \mathrm{m}$ ).

at $650 \mathrm{~nm}$, respectively, ${ }^{37-39}$ which guaranteed its excellent photodynamic and photothermal effects. As shown in Fig. 3a, when the concentration of CIO reached $300 \mu \mathrm{g} \mathrm{mL}{ }^{-1}$, the temperature rose by about $40{ }^{\circ} \mathrm{C}$ upon $808 \mathrm{~nm}$ laser irradiation, suggesting an excellent photothermal effect. ${ }^{26,33,37,40}$ The photothermal conversion efficiency of CIO was $35.76 \%$ (Fig. S7 and Table S1, ESI $\dagger$ ). In addition, compared with free ICG, CIO shows superior photostability (Fig. 3b). Fig. S8 (ESI $\dagger$ ) shows the infrared thermal images of CIO both in vitro and in vivo. The temperature rose rapidly under $808 \mathrm{~nm}$ laser irradiation, showing a good lightto-heat conversion performance in vitro. The in vivo thermal images show that the temperature rose from 21 to $63.5{ }^{\circ} \mathrm{C}$ within 5 min after injection of CIO nanoparticles.

To evaluate the photodynamic effect, 1,3-diphenylisobenzofuran (DPBF) was used as a molecular probe to detect the generated ${ }^{1} \mathrm{O}_{2}$ under $650 \mathrm{~nm}$ laser irradiation. As shown in Fig. $3 \mathrm{c}$ and $\mathrm{d}$ and Fig. S9 (ESI $\dagger$ ), more ${ }^{1} \mathrm{O}_{2}$ was produced from CIO over time; however, no obvious decrement in the absorption of DPBF was observed in the absence of CIO, which implied that ${ }^{1} \mathrm{O}_{2}$ was produced efficiently from CIO upon NIR laser irradiation. Meanwhile, 2,7-dichlorodihydrofluorescein (DCFH-DA) was chosen as a reactive oxygen species (ROS) probe to study the intracellular ROS generation. Fig. 3e shows the fluorescence photographs of CT26 cells treated with different methods. Compared with the other three groups, the fluorescence intensity was significantly enhanced for the CIO + NIR group, which also confirmed that ROS were produced from CIO under laser irradiation. Overall, the good photostability and excellent photodynamic and photothermal effects make CIO a potential photosensitizer for PDT and PTT.

\section{Cellular uptake and the cytotoxic effect of CIO}

Subsequently, the intracellular uptake process of CIO was investigated. CT26 cells were treated with CIO for different times. As shown in Fig. 4a, the significantly increased fluorescence intensity over time proved that CIO could be effectively internalized by the CT26 cells. The standard 3-(4,5-dimethylthiazol-2yl)-2,5-diphenyl tetrazolium bromide (MTT) assay was performed on the fibroblast cell line (L929) and CT26 to study the in vitro biocompatibility and cytotoxicity of CIO, respectively. The survival rates of L929 and CT26 cells were still above 90\% at a concentration of $200 \mu \mathrm{g} \mathrm{mL}{ }^{-1}$, implying the low toxicity and excellent biocompatibility of CIO (Fig. $4 \mathrm{~b}$ and c and Fig. S12b, ESI $\dagger$ ). Moreover, the cytotoxicity of the COF in vitro was investigated. The survival rate of L929 cells was also above $85 \%$ at a concentration of $100 \mu \mathrm{g} \mathrm{mL} \mathrm{m}^{-1}$ (Fig. S11, ESI $\dagger$ ). The cytotoxic effect of CIO nanoparticles on CT26 cells under NIR laser irradiation was studied. The survival rate for the CIO + PDT + PTT group declined obviously under NIR laser irradiation and only $10 \%$ of cells survived when the concentration reached $200 \mu \mathrm{g} \mathrm{mL} \mathrm{m}^{-1}$ (Fig. 4c), which demonstrated that CT26 cells could be killed effectively with the combination of PTT and PDT under laser irradiation. The phototherapeutic effect of CIO was further confirmed by flow cytometry and Annexin V-FITC/PI co-staining assay. As shown in Fig. S10 (ESI $\dagger$ ), a significantly increased cell apoptosis proportion was observed for the CIO + PDT + PTT group under laser irradiation.

\section{Photodynamic and photothermal effect of CIO in vivo}

The therapeutic efficacy of CIO in vivo was further evaluated based on the $\mathrm{H} 22$ tumor-bearing mice model. ${ }^{33,38,41,42}$ Mice were randomly divided into eight groups ( $n=6$, per group), i.e., (i) pure PBS (control group), (ii) PBS + PDT, (iii) PBS + PTT,

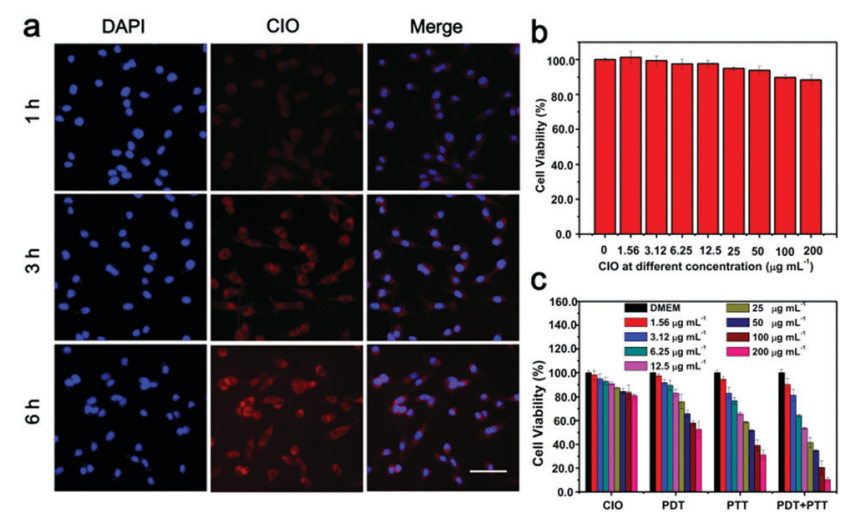

Fig. 4 (a) Fluorescence images of the endocytosis process with $\mathrm{ClO}$ nanoparticles (scale bar is $50 \mu \mathrm{m}$ ). (b) Cytotoxicity assay of L929 cells incubated with $\mathrm{ClO}$ at different concentrations $(0,1.56,3.12,6.25,12.5,25$, 50,100 , and $200 \mu \mathrm{g} \mathrm{mL}^{-1}$ ) for $24 \mathrm{~h}$. (c) Relative cell viability against CT26 cells for $\mathrm{ClO}, \mathrm{ClO}+\mathrm{PDT}, \mathrm{ClO}+\mathrm{PTT}$, and $\mathrm{ClO}+\mathrm{PDT}+\mathrm{PTT}$. 
(iv) PBS + PDT + PTT, (v) CIO only, (vi) CIO + PDT, (vii) CIO + PTT, and (viii) CIO + PDT + PTT. The slightly increased mean body weight during the treatment further proved the good biocompatibility of CIO in vivo (Fig. 5a). As shown in Fig. 5b and $\mathrm{c}$, the relative tumor volume for the (i)-(v) groups increased rapidly, indicating the negligible therapeutic effect of nearinfrared light irradiation or nanoparticles alone. However, the relative tumor volume for the (vi)-(viii) groups gradually decreased, which implied that the tumor growth was efficiently inhibited in the presence of CIO nanoparticles under nearinfrared laser irradiation. Importantly, since CIO could generate ROS under $650 \mathrm{~nm}$ laser irradiation and convert light into heat under $808 \mathrm{~nm}$ laser irradiation, the tumors in the CIO + PDT + PTT group were eliminated completely and the best therapeutic effect was achieved with the combination of PTT and PDT. The hematoxylin and eosin (H\&E) stained images revealed that no significant damage to the major organs occurred for these COF-based materials (Fig. 5d and Fig. S12a, ESI $\dagger$ ). Moreover, the accumulation and biodistribution of CIO in vivo were further studied (Fig. S13, ESI $\dagger$ ). The contents of nanoparticles in the liver and kidneys were relatively higher in the first $12 \mathrm{~h}$, but with the extension of time, the contents gradually decreased and a high content of nanoparticles was detected in the feces, which proved that most of the CIO nanoparticles could be cleared from the body after 7 days.

\section{CIO nanoparticle mediated immunotherapy}

The primary tumor could be effectively suppressed by using CIO nanoparticles with the combinational PTT and PDT treatments in this study. In order to inhibit the tumor metastasis by immunotherapy, CIO nanoparticles were further combined with anti-PD-L1 checkpoint blockade to activate the immune

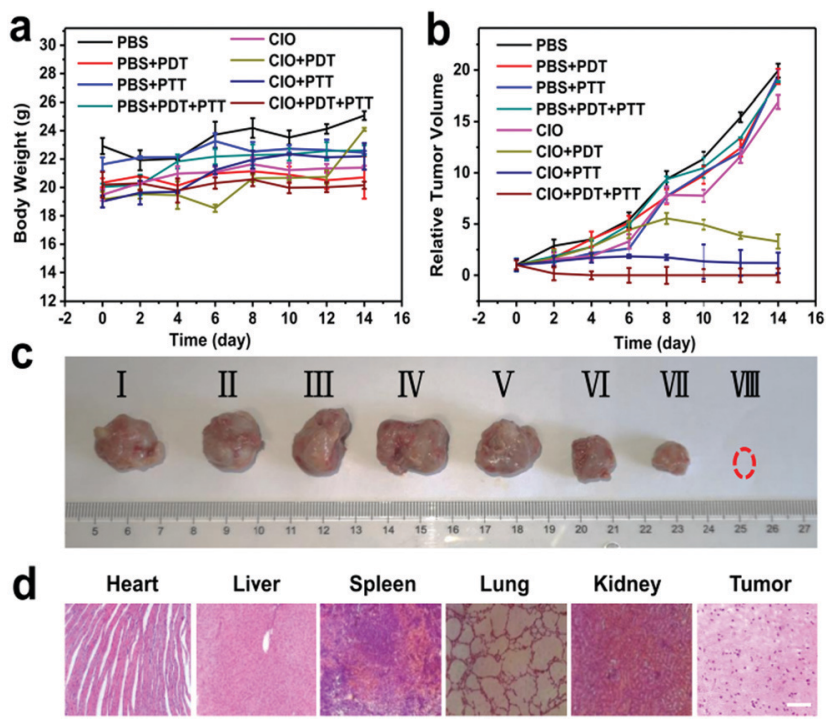

Fig. 5 (a) Body weight and (b) relative tumor volume of the tumorbearing mice after different treatments. (c) In vivo antitumor efficacy of $\mathrm{ClO}$ tumor-bearing mice. (d) H\&E stained images of heart, liver, spleen, lungs, kidneys and tumors obtained from the tumor-bearing mice with $\mathrm{ClO}+$ PDT + PTT treatments (scale bar $=50 \mu \mathrm{m}$ ). system to recognize and eradicate residual cancer cells at the specific site of metastasis.

CT26 cells were subcutaneously injected into the left flank of $\mathrm{BALB} / \mathrm{c}$ female mice. When the average tumor volume reached about $60 \mathrm{~mm}^{3}$, the second tumor was subcutaneously injected on the right side as the distant tumor. The tumor-bearing mice were randomly divided into four groups $(n=6)$ and treated with (i) pure PBS (control group), (ii) PBS + anti-PD-L1, (iii) CIO + PDT + PTT, and (iv) CIO + PDT + PTT + anti-PD-L1, respectively. As shown in Fig. 6a, on day 0, the primary tumors (located in the left flank) were treated with different methods. Subsequently, anti-PD-L1 was intravenously injected with a dose of $25 \mu \mathrm{g}$ per mouse on day 1, 3, 5 and 7, respectively.

To understand the mechanism of the anti-tumour effect triggered by CIO based PPT and PDT in combination with antiPD-L1 therapy, immune cells in the draining lymph node were collected for analysis. ${ }^{43}$ As shown in Fig. S14a and c (ESI $\dagger$ ), the percentage of CD8 + cytotoxic T lymphocytes (CTLs) in the draining lymph node of mice significantly increased to $29.7 \%$ after the CIO-based PTT and PDT plus anti-PD-L1 treatment, which was higher than those groups treated with anti-PD-L1 (15.9\%) or CIO-based PPT and PDT (19.7\%). CD4 + T cells help to promote immune responses. There was a mass of CD4 $+\mathrm{T}$ cells accumulated in the draining lymph node of mice after being treated with CIO-based PTT and PDT plus anti-PD-L1 (Fig. S14b and d, ESI $\dagger$ ). In addition, inhibitory cytokines secreted by tumor tissue (IL-10 and TGF- $\beta 1$ ) can also be drained to regional lymph nodes to affect the function of $\mathrm{T}$ cells in draining lymph nodes. So, immunosuppressive cytokine secretion in tumors was then investigated. As shown in Fig. S14e and $\mathrm{f}$ (ESI $\dagger$ ), the percentage of interleukin 10 (IL-10) and transforming growth factor beta 1 (TGF- $\beta 1$ ) upon treatment with CIO-based PTT and PDT plus anti-PD-L1 was much lower than that of the control group. Therefore, after CIO-based PDT/ PTT plus anti-PD-L1 treatment, the CD4 + T cells and infiltration of CD8 + $\mathrm{T}$ cells in the lymph nodes of mice showed an active anti-tumor immune response.

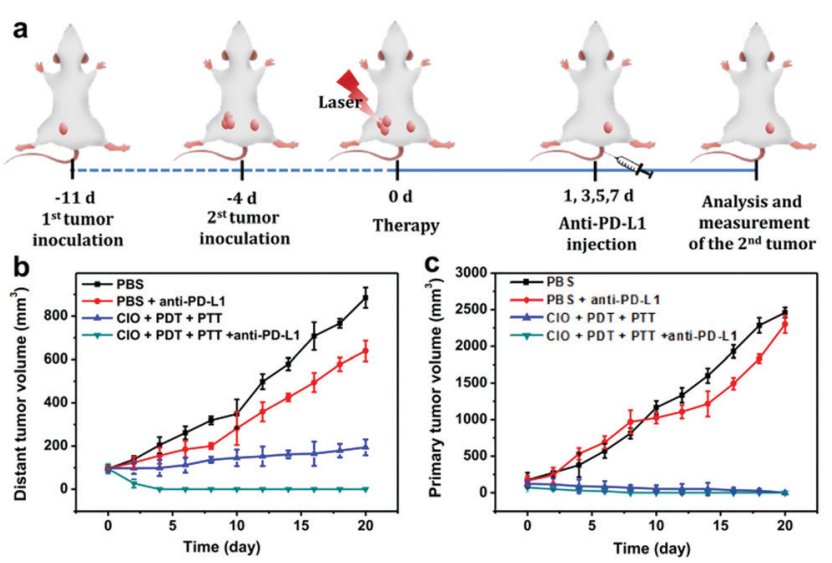

Fig. 6 (a) Scheme of $\mathrm{ClO}$-based synergistic comprehensive treatment combined with anti-PD-L1 checkpoint blockade treatment for bilateral tumor models in BALB/c mice. (b) Distant tumor volume and (c) primary tumor volume in BALB/c mice with different treatments. 


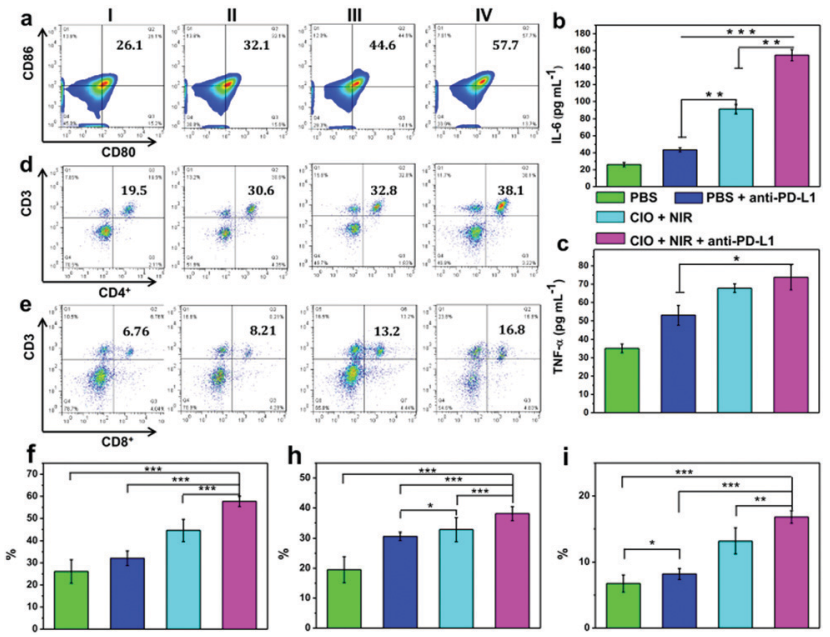

Fig. 7 (a) Quantification of CD80 and CD86 expression on the surface of DCs in lymph nodes after different treatments. (I) PBS; (II) PBS + antiPD-L1; (III) $\mathrm{ClO}$ + PDT + PTT; (IV) ClO + PDT + PTT + anti-PD-L1 (b) Secretion level of TNF- $\alpha$ and (c) IL- 6 by splenocytes obtained from immunized mice. ANOVA was used to assess statistical significance: ${ }^{*} p<0.5,{ }^{* *} p<0.01$, and ${ }^{* * *} p<0.001$. (d) Flow cytometric analyses of the population of CD4+ (CD3 + CD4+ as the marker) T cells in tumors of mice after various treatments. (e) Flow cytometric analyses of the populations of CD8+ (CD3 + CD8+ as the marker) $T$ cells in tumors of mice after various treatments. (f-i) Data of CD80 + CD86, CD3 + CD4+ and CD3 + CD8+ were expressed as mean \pm SD $(n=3)\left({ }^{*} p<0.05\right.$; ${ }^{* *} p<0.01 ;$ and $\left.{ }^{* * *} p<0.001\right)$.

As the main antigen-presenting cells, DC cells play an important role in specific immune response. DCs could capture these antigens, and then present to $\mathrm{T}$ cells through major histocompatibility complex class I and II (MHC I and II) molecules, which can induce the responses of cytotoxic T lymphocytes (CTLs) and are also important for eradicating tumor cells. ${ }^{44-47}$ Based on the "immune escape mechanism" of tumors, an inhibitor named PD-L1 was developed, which could block the binding of PD-1 and PD-L1. Consequently, T cells can restore the immune function weakened by tumor cells and effectively activate the immune response. Fig. $6 \mathrm{~b}$ and $\mathrm{c}$ indicate that the CIO + PDT + PTT and $\mathrm{CIO}+\mathrm{PDT}+\mathrm{PTT}+$ anti-PD-L1 groups can not only ablate primary tumor but also significantly inhibit the growth of second tumor, suggesting the successful initiation of systemic immunity. The mice were sacrificed on day 8 , and then the distant tumors, lymph nodes and spleen were taken out for further analysis. The distant tumor was stained with H\&E for histopathological analysis. As shown in Fig. S15 (ESI $\dagger$ ), the tumor tissues were seriously damaged for the CIO + PDT + PTT + anti-PD-L1 group, implying the good immunotherapy effect. CD80 and CD86 are important indicators and markers of DC cell maturity after inducing a T cell-mediated immune response. ${ }^{48}$ The inguinal lymph nodes were analyzed by flow cytometry after being co-stained with CD11c (the DC marker), CD80 and CD86. The percentage of matured DCs (CD11c, CD80 and CD86) increased from $26.1 \%$ to $57.7 \%$ for the CIO + PDT + PTT + anti-PD-L1 group, while these values rose only to $32.1 \%$ and 44.6\% for the PBS + anti-PD-L1 and CIO + PTT + PDT groups, respectively (Fig. 7a and f). The secretion of cytokines is also a

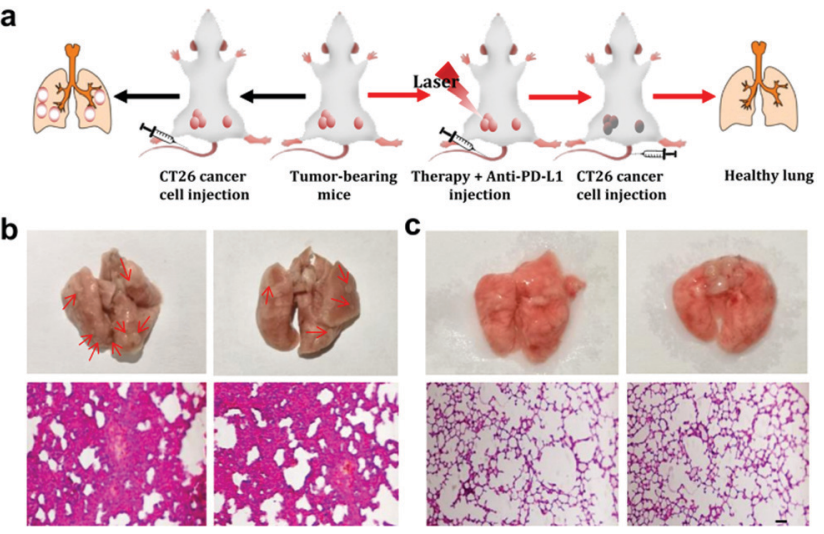

Fig. 8 (a) Scheme of $\mathrm{ClO}$-based synergistic comprehensive treatment combined with anti-PD-L1 checkpoint blockade treatment for lung metastasis inhibition in BALB/c mice. (b) Representative images of lung tissues with metastatic nodules indicated by red arrows and H\&E staining of lung tissues. (c) Pictures of treatment group lungs and H\&E staining of lung tissues (scale bar $=100 \mu \mathrm{m}$ ).

important in the process of immune responses, and the enzymelinked immunosorbent assay (ELISA) was further used to detect the amount of different cytokines such as interleukin 6 (IL-6) and tumor necrosis factor $\alpha$ (TNF- $\alpha)$ in the supernatant of mouse splenocytes. Similarly, although the anti-PD-L1 or PDT + PTT + CIO group was able to increase the secretion of pro-inflammatory cytokines, their secretions induced by CIO + PDT + PTT + anti-PD-L1 were obviously higher and lasted longer, which is favorable for triggering the antitumor immune response (Fig. $7 \mathrm{~b}$ and c). In addition, the frequency of CD4+ (CD3 + CD4+ as the marker) and $\mathrm{CD} 8+(\mathrm{CD} 3+\mathrm{CD} 8+$ as the marker) $\mathrm{T}$ cells of the distant tumor and spleen was further examined by flow cytometry analysis. As shown in Fig. 7d, e, h, i and Fig. S16 and S17 (ESI $\dagger$ ), compared with the other three groups, the highest percentage of tumor-infiltrating cytotoxic $\mathrm{T}$ lymphocytes CD8+ and helper T lymphocytes CD4+ was observed for the CIO + PDT + PTT + anti-PD-L1 group, which demonstrated that the $\mathrm{T}$ cell-mediated tumor immunity was effectively activated. Moreover, a CT26 tumor model of lung metastasis was established to further study the antitumor effect of combinational PTT, PDT and anti-PD-L1 checkpoint blockade therapy. As shown in Fig. 8a, the model was established by the intravenous injection of CT26 cancer cells into the mice treated with CIO + PDT + PTT + anti-PD-L1 and untreated mice, respectively. Then, lung tissues were collected after 20 days (Fig. 8b, red arrows show the lung metastasis nodules). Compared with untreated mice, no metastatic nodules were observed for the CIO + PDT + PTT + anti-PD-L1 group, which was further verified by H\&E staining images of lung slices (Fig. 8c). All the results demonstrated that $\mathrm{CIO}$ dual-mode therapy combined with anti-PD-L1 blockade therapy could trigger strong immune responses safely and effectively, which shows enormous potential for future clinical cancer immunotherapy.

\section{Conclusions}

A COF@ICG@OVA based therapeutic platform was prepared at room temperature under mild conditions with a short 
reaction time. The photostability of ICG was greatly enhanced by using the COF as the host material. The COF@ICG@OVA nanoparticles showed excellent photodynamic and photothermal effects due to their relatively high photothermal conversion efficiency and the ability to generate ROS under $650 \mathrm{~nm}$ laser irradiation. Tumor-associated antigens were released after the ablation of the primary tumor with the combinational PTT and PDT, which induced systemic immunity and effectively inhibited tumor metastasis by further combination with PD-L1 checkpoint blockade therapy. This study demonstrated the potential utilization of COF based materials for the inhibition of tumor metastasis, and also opens a new way to construct multifunctional therapeutic platforms for various biomedical applications.

\section{Conflicts of interest}

The authors declare no conflict of interest.

\section{Acknowledgements}

This project is financially supported by the National Natural Science Foundation of China (NSFC 21471145), the Science and Technology Development Planning Project of Jilin Province (20170101179JC), and the "Hundred Talents Program" of the Chinese Academy of Science.

\section{References}

1 A. Jemal, F. Bray, M. M. Center, J. Ferlay, E. Ward and D. Forman, Ca-Cancer J. Clin., 2011, 61, 69-90.

2 M. Chang, M. Wang, M. Wang, M. Shu, B. Ding, C. Li, M. Pang, S. Cui, Z. Hou and J. Lin, Adv. Mater., 2019, 31, 1905271.

3 M. Yilmaz, G. Christofori and F. Lehembre, Trends Mol. Med., 2007, 13, 535-541.

4 W. Zhang, S. Song, H. Wang, Q. Wang, D. Li, S. Zheng, Z. Xu, H. Zhang, J. Wang and J. Sun, Biomaterials, 2019, 217, 119279.

5 S. Hamdy, A. Haddadi, R. W. Hung and A. Lavasanifar, Adv. Drug Delivery Rev., 2011, 63, 943-955.

6 W.-Y. Sheng and L. Huang, Pharm. Res., 2011, 28, 200-214.

7 B. M. Carreno, V. Magrini, M. Becker-Hapak, S. Kaabinejadian, J. Hundal, A. A. Petti, A. Ly, W.-R. Lie, W. H. Hildebrand and E. R. Mardis, Science, 2015, 348, 803-808.

8 K. Palucka and J. Banchereau, Nat. Rev. Cancer, 2012, 12, 265-277.

9 P. W. Kantoff, C. S. Higano, N. D. Shore, E. R. Berger, E. J. Small, D. F. Penson, C. H. Redfern, A. C. Ferrari, R. Dreicer and R. B. Sims, N. Engl. J. Med., 2010, 363, 411-422.

10 M. M. Gubin, X. Zhang, H. Schuster, E. Caron, J. P. Ward, T. Noguchi, Y. Ivanova, J. Hundal, C. D. Arthur and W.-J. Krebber, Nature, 2014, 515, 577-581.

11 D. M. Pardoll and Nat. Rev, Cancer, 2012, 12, 252-264.

12 K. J. Curran and R. J. Brentjens, J. Clin. Oncol., 2015, 33, 1703-1706.
13 S. L. Maude, N. Frey, P. A. Shaw, R. Aplenc, D. M. Barrett, N. J. Bunin, A. Chew, V. E. Gonzalez, Z. Zheng and S. F. Lacey, N. Engl. J. Med., 2014, 371, 1507-1517.

14 M. Kalos and C. H. June, Immunity, 2013, 39, 49-60.

15 N. P. Restifo, M. E. Dudley and S. A. Rosenberg, Nat. Rev. Immunol., 2012, 12, 269-281.

16 Q. Chen, M. Chen and Z. Liu, Chem. Soc. Rev., 2019, 48, 5506-5526.

17 K. Deng, C. Li, S. Huang, B. Xing, D. Jin, Q. Zeng, Z. Hou and J. Lin, Small, 2017, 13, 1702299.

18 H. Abrahamse and M. R. Hamblin, Biochem. J., 2016, 473, 347-364.

19 H. Zhu, P. Cheng, P. Chen and K. Pu, Biomater. Sci., 2018, 6, 746-765.

20 X. Duan, C. Chan and W. Lin, Angew. Chem., Int. Ed., 2019, 58, 670-680.

21 X. Dong, J. Liang, A. Yang, Z. Qian, D. Kong and F. Lv, Biomaterials, 2019, 209, 111-125.

22 B. Ding, S. Shao, C. Yu, B. Teng, M. Wang, Z. Cheng, K. L. Wong, M. Pang and J. Lin, Adv. Mater., 2018, 30, 1802479.

23 C. Liang, L. Xu, G. Song and Z. Liu, Chem. Soc. Rev., 2016, 45, 6250-6269.

24 X. Feng, W. Xu, Z. Li, W. Song, J. Ding and X. Chen, Adv. Sci., 2019, 6, 1900101.

25 V. Saxena, M. Sadoqi and J. Shao, Eur. J. Pharm. Sci., 2003, 92, 2090-2097.

26 X. Cai, B. Liu, M. Pang and J. Lin, Dalton Trans., 2018, 47, 16329-16336.

27 N. Huang, R. Krishna and D. Jiang, J. Am. Chem. Soc., 2015, 137, 7079-7082.

28 P. Pachfule, S. Kandambeth, D. D. Díaz and R. Banerjee, Chem. Commun., 2014, 50, 3169-3172.

29 V. Vyas, Chem. Mater., 2016, 28, 5191-5204.

30 G. Lin, H. Ding, D. Yuan, B. Wang and C. Wang, J. Am. Chem. Soc., 2016, 138, 3302-3305.

31 X. Feng, L. Liu, Y. Honsho, A. Saeki, S. Seki, S. Irle, Y. Dong, A. Nagai and D. Jiang, Angew. Chem., Int. Ed., 2012, 51, 2618-2622.

32 S. Gan, X. Tong, Y. Zhang, J. Wu, Y. Hu and A. Yuan, Adv. Funct. Mater., 2019, 29, 1902757.

33 C. Hu, L. Cai, S. Liu and M. Pang, Chem. Commun., 2019, 55, 9164-9167.

34 S. Liu, Y. Liu, C. Hu, X. Zhao and M. Pang, Chem. Commun., 2019, 55, 6269-6272.

35 D. Rodríguez-San-Miguel, A. Yazdi, V. Guillerm, J. PérezCarvajal, V. Puntes, D. Maspoch and F. Zamora, Chem. - Eur. J., 2017, 23, 8623-8627.

36 J. Pan, Y. Wang, C. Zhang, X. Wang, H. Wang, J. Wang, Y. Yuan, X. Wang, X. Zhang and C. Yu, Adv. Mater., 2018, 30, 1704408.

37 C. Hu, Y. Shi, C. Sun, S. Liang, S. Bao and M. Pang, Chem. Commun., 2018, 54, 4862-4865.

38 Y. Shi, X. Deng, S. Bao, B. Liu, Z. Cheng, M. Pang and J. Lin, Chem. - Asian J., 2017, 12, 2183-2188.

39 C. Hu, Z. Zhang, S. Liu, X. Liu and M. Pang, ACS Appl. Mater. Interfaces, 2019, 11, 23072-23082. 
40 X. Cai, X. Deng, Z. Xie, Y. Shi, M. Pang and J. Lin, Chem. Eng. J., 2019, 358, 369-378.

41 S. Liu, C. Hu, Y. Liu, X. Zhao, M. Pang and J. Lin, Chem. Eur. J., 2019, 25, 4315-4319.

42 X. Zhao, Z. Zhang, X. Cai, B. Ding and M. Pang, ACS Appl. Mater. Interfaces, 2019, 11, 7884-7892.

43 Q. Chen, L. Xu, C. Liang, C. Wang, R. Peng and Z. Liu, Nat. Commun., 2016, 7, 13193.

44 C. H. Kapadia, J. L. Perry, S. Tian, J. C. Luft and J. M. DeSimone, J. Controlled Release, 2015, 219, 167-180.
45 Z. S. Dunn, J. Mac and P. Wang, Biomaterials, 2019, 119265. 46 Q. Chen, Q. Hu, E. Dukhovlinova, G. Chen, S. Ahn, C. Wang, E. A. Ogunnaike, F. S. Ligler, G. Dotti and Z. Gu, Adv. Mater., 2019, 31, 1900192.

47 J. C. Huh, D. H. Strickland, F. L. Jahnsen, D. J. Turner, J. A. Thomas, S. Napoli, I. Tobagus, P. A. Stumbles, P. D. Sly and P. G. Holt, J. Exp. Med., 2003, 198, 19-30.

48 Z. Wang, P. Huang, O. Jacobson, Z. Wang, Y. Liu, L. Lin, J. Lin, N. Lu, H. Zhang and R. Tian, ACS Nano, 2016, 10, 3453-3460. 